Document downloaded from:

http://hdl.handle.net/10251/69638

This paper must be cited as:

Rentocchini, F.; D'este, P.; Manjarres Henriquez, LA.; Grimaldi, R. (2014). The relationship between academic consulting and research performance: Evidence from five Spanish universities. International Journal of Industrial Organization. 32:70-83. doi:10.1016/j.ijindorg.2013.11.001.

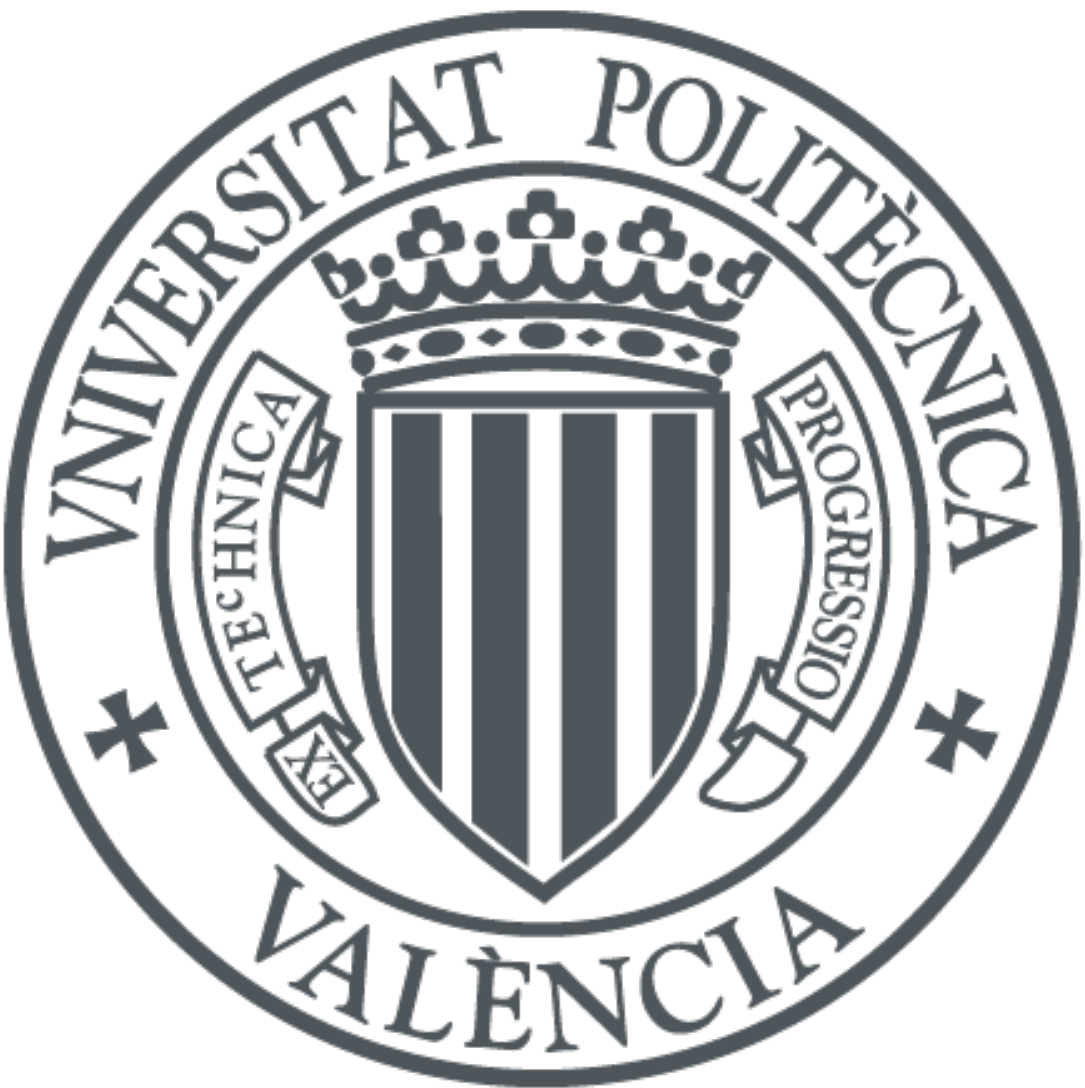

The final publication is available at

http://dx.doi.org/10.1016/j.ijindorg.2013.11.001

Copyright Elsevier

Additional Information 


\title{
The relationship between academic consulting and research performance: evidence from five Spanish universities
}

\author{
Francesco Rentocchini $^{a c \#}$, Pablo D'Este ${ }^{a}$, Liney Manjarrés-Henríquez ${ }^{a d}$, Rosa Grimaldi $^{b}$ \\ ${ }^{a}$ INGENIO [CSIC-UPV], Universidad Politécnica de Valencia, Spain \\ ${ }^{b}$ Department of Management, University of Bologna, Italy \\ ${ }^{c}$ Department of Economics and Management, University of Trento, Italy \\ ${ }^{d}$ Departamento de Ingeniería Industrial. Universidad Autónoma del Caribe, Colombia
}

\begin{abstract}
This paper investigates the relationship between engagement in consulting activities and the research performance of academic scientists. The study relies on a sample of 2678 individual faculty, from five Spanish universities, who have been recipients of publicly funded grants or have been principal investigators in activities contracted by external agents over the period 1999-2004. By implementing a propensity score matching estimator method, we show that engaging in consulting activities has an overall negative relationship with the average number of ISIpublications. However, the effect of consulting on the scientific productivity of academic scientists depends on the scientific fields and the intensity of engagement in consulting activities. Academic consulting is found to be negatively correlated with the number of publications in the fields of 'Natural and Exact Sciences' and 'Engineering', but not in the case of 'Social Sciences and Humanities'. When the intensity of consulting activity is taken into account at the discipline level, we find that engaging in consulting activities is negatively correlated with scientific productivity only for high levels of involvement in consulting activities, but not for moderate ones.
\end{abstract}

JEL Classification: O31; O32; O33; Z19; L31

Keywords: academic consulting; economics of science; technology transfer

Acknowledgements: A preliminary version of this paper was presented to the DRUID summer conference 2011. The authors are grateful to the conference participants for their comments and suggestions. We would like to thank two anonymous referees and the editors of the Journal for their very useful and detailed comments. Pablo D'Este acknowledges support from the Spanish Ministry of Economy and Competitiveness (ECO2011-28749). Francesco Rentocchini acknowledges funding from the Autonomous Province of Trento (Grant 2009 Outgoing: OVERNET). The usual caveats apply.

\footnotetext{
\# Corresponding author: Department of Economics, Faculty of Economics, via Inama 5, I-38122, Trento, Italy, e-mail: francesco.rentocchini@economia.unitn.it, Tel: 00390461 882162, Fax: 00390461882222
} 


\section{INTRODUCTION}

The engagement of scientists in knowledge and technology transfer activities is a topic that has attracted an increasing amount of interest in the last years, both among scholars and policy makers. Governments worldwide have been calling for greater interaction between universities and industry, under the rationale that this interaction is instrumental to foster technological development and economic achievements (OECD, 2003; DIUS, 2008; Dutrenit and Arza, 2010) and to strengthen the co-evolution between scientific contributions and commercial opportunities (Rosenberg \& Nelson, 1994; Veugelers \& Cassiman, 2005). At the same time, sceptics have raised concerns about a possible negative impact that universities’ involvement in technology transfer can have on the production and advancement of scientific knowledge production (Krimsky, 2003).

Studies looking at the impact of universities' involvement in knowledge and technology transfer on scientific productivity have focused on a limited set of mechanisms of technology transfer, mostly including patents and academic spin-offs (Agrawal and Henderson, 2002; Azoulay et al., 2009; Toole and Czarnitzki, 2010), and to a lesser extent research collaborations (Gulbrandsen and Smeby, 2005; Lee and Bozeman, 2005). The impact on scientific production of the overall external engagement activities by scientists might be underestimated as a result of neglecting other forms of university-industry knowledge and technology transfer, encompassing consulting, R\&D contracts, personnel exchange or joint student supervision, which have received less attention in the literature (Schartinger et al., 2002; D'Este and Patel, 2007).

Moving from these premises, this paper focuses on one of these less traceable and often informal mechanisms of external engagement by scientists, represented by academic consulting. In our view the current lack of systematic analysis of academic consulting is particularly unfortunate because academic consulting is a comparatively more frequent phenomenon than other means of engagement in knowledge transfer activities by academic scientists (i.e. patents, spin-offs or joint research collaborations); it is often a critical channel through which university research impacts on industrial R\&D (Cohen et al., 2002; Arvanitis et al., 2008; Bekkers and Bodas-Freitas, 2008); and it is also appreciable as a stream of income for university in general, and for academic scientists in particular (Perkmann and Walsh, 2008).

Drawing upon the above discussion, this study investigates the relationship between engagement in consulting activities and the research performance of academic scientists. To investigate this, we 
rely on a sample of 2678 individual faculty, from the five universities of the Valencian Higher Education system, who have been recipients of publicly funded grants or have been principal investigators in R\&D contracts over the period 1999-2004.

Our findings show that engaging in consulting activities is negatively correlated with the average number of ISI-publications in the subsequent period. However, the effect of consulting on the scientific productivity of academic scientists varies across different scientific fields and for different levels of intensity in consulting activities. Academic consulting is found to be negatively related to scientific productivity in the fields of Natural and Exact Sciences and Engineering, but not in the cases of Medical Sciences and Social Sciences and Humanities. When the intensity of consulting activity is taken into account (within each of these disciplines), engaging in consulting activities is negatively related to scientific productivity only for high levels of involvement in consulting activities, but not for low or moderate levels.

The paper is structured as follows. Section 2 reviews the relevant literature and puts forward the main research questions of this study; Section 3 describes the data used in the analysis, while Section 4 provides an explanation of the methodology. Section 5 presents the results and Section 6 concludes.

\section{LITERATURE BACKGROUND}

This section provides a brief overview of the literature that investigates the relationship between knowledge transfer activities and scientific performance, and it discusses the conflicting arguments regarding the impact of academic consulting on scientific productivity.

\subsection{Knowledge transfer activities and scientific productivity: an overview}

The impact of knowledge transfer activities on research performance has become a key area of concern for both scholars and policy makers interested in assessing the social and economic impact of the engagement of university scientists with non-academic communities. Despite the increasing amount of empirical evidence regarding the impact on research productivity of academic entrepreneurial behavior and knowledge transfer activities, the extant literature remains quite inconclusive, providing mixed findings which reflect different views in an ongoing open debate.

At one end of the spectrum there are advocates of universities' involvement in technology transfer who welcome scientists' engagement in knowledge transfer activities, arguing that closer contacts 
between industrial and academic research will bring benefits to both industrialists and academic researchers. The underlying rationale for this argument is that interaction with the private sector provides scientists with important learning and financial opportunities, thus inducing a complementary effect between research and interaction with industry. In particular, involvement in knowledge transfer provides a setting in which academic researchers might identify new and relevant research topics, take advantage of competences and infrastructure available in firms and benefit from financial pay-offs of successful commercialization of research outputs (Van Looy et al., 2006; Breschi et al., 2007; Buenstorf, 2009).

On the other hand, sceptics hold that the increasing incentives for academic patenting and licensing that have occurred over the last two decades (Mowery et al., 2002) has raised several concerns about the potentially negative effects that the commercialization of scientific discoveries could have on the conduct of academic researchers. In particular, it has been argued that financial incentives from patenting and licensing could shift the orientation of scientists away from basic and towards applied research, and could also undermine their commitment to the norms of open science, thereby leading to undesirable behaviors, such as data withholding, secrecy and publication delays (Blumenthal et al., 1996; Krimsky, 2003; Link \& Scott, 2003).

From an empirical point of view, there are several contributions that have addressed this issue drawing mostly upon data on academic patenting and engagement in spin-off activities, reaching conflicting conclusions. Fabrizio and DiMinin (2008), Stephan et al. (2007) and Azoulay et al. (2009) have found a statistically positive effect of researchers' patenting on publication counts. Findings by Breschi et al $(2007 ; 2008)$ reveal that academic inventors tend to publish more and produce higher quality papers than their non-patenting colleagues, and increase further their productivity after patenting. The beneficial effect of patenting on publication rates last longer for serial inventors, that is, academic inventors with more than one patent.

There are also findings in support of negative effects, portraying a tradeoff between patenting and the progress of academic science. Surveys of academic scientists have suggested that patenting skews scientists' research agendas toward commercial priorities, causes delay in the public dissemination of research findings and crowds out efforts devoted to research (Blumenthal et al., 1996; Campbell et al., 2002; Krimsky, 2003). The main argument in this case is centered on the idea that research and entrepreneurial activities are competing for researcher's limited time and thus a substitution effect is in place between time dedicated to develop new research ideas and time 
spent in commercializing these ideas. In line with this argument, Calderini et al. (2009) find evidence of a substitution effect between patenting and publishing when publications in basic sciences are taken into account. Buenstorf (2009) in a study based on academic spin-offs finds that, in the long run, founding a spin-off may be detrimental to the quantity and quality of a researcher's output. In the same vein, Toole and Czarnitzki (2010) highlight the existence of a significant decrease in the research performance of US academic scientists when they start working on commercialization through the creation of for-profit firms; while Hottenrott \& Thorwarth (2011) find a negative and significant relationship between the amount of industry funding and the quantity and quality of research carried out.

Finally, some studies have suggested the existence of a curvilinear relationship between the extent of engagement in knowledge transfer activities and research productivity. For instance, Crespi et al. (2011) suggest that academic patenting is complementary to publishing at least up to a certain level of patenting output after which there is evidence of a substitution effect. While, looking at softer forms of engagement such as research collaboration and contract research with industry, ManjarrésHenríquez et al. (2009) and Larsen (2011) find that complementarities with research productivity exist only for moderate levels of knowledge transfer engagement.

\subsection{Scientists' engagement in consulting activities and scientific productivity}

Studies looking at the relationship between academic consulting and research performance are rare when compared to the attention placed on other forms of knowledge transfer activities such as patenting, spin-off activities or joint-research partnerships. This is unfortunate because academic consulting is a channel of knowledge transfer that deserves thoughtful consideration on its own right for at least the following three reasons.

First, academic consulting is a widespread phenomenon. Compared to other means of engagement in knowledge transfer activities by academic scientists, such as patents and spin-offs, consulting exhibits a much higher prevalence among university researchers. Indeed, involvement in consulting is not the prerogative of academics in certain scientific disciplines, but an activity that is prevalent across many scientific fields (Bird and Allen, 1989; Louis et al., 1989; D’Este and Patel, 2007; Landry et al., 2010). Even though the figures on the proportion of academic scientists involved in consulting differ across studies, ranging from 18\% (Bozeman and Gaughan, 2007), to 31\% (Gulbrandsen and Smeby, 2007) or 38\% (D’Este and Perkmann, 2011), academic consulting is 
systematically reported among the most frequent channels of interaction with non-academic communities.

Second, as several studies have revealed, academic consulting is often a critical channel in the process of knowledge and technology transfer between university and industry. As Cohen et al. (2002), Arvanitis et al. (2008) and Bekkers and Bodas-Freitas (2008) show, consulting is a key channel through which university research impacts on industrial R\&D. Similarly, Thursby et al. (2001) have shown that the large majority of licensed inventions from university research requires inventors' assistance for being successfully commercialized. Finally, consulting activity is also appreciable as a stream of income for university in general, and academic scientists in particular. For example, academic researchers in the UK earned, on average, an extra of $2458 £$ in 2006 thanks to consulting activities, an order of magnitude similar to the source of funding from R\&D contracts with industry, and consistently above the figures accounted by royalty income from licenses or spin-offs (Perkmann and Walsh, 2008).

Given the high rate of occurrence of academic consulting, it is reasonable to raise questions about its impact on scientific performance, in a similar vein as it has been done for other forms of knowledge transfer. Even though scholars have under-investigated the subject (some notable exceptions being Boyer and Lewis, 1984; Rebne, 1989; Mitchell and Rebne, 1995; and Perkmann and Walsh, 2008), it is possible to identify arguments anticipating a positive impact of consulting on scientific productivity, as well as arguments in support of a negative impact of academic consulting on scientific productivity. We discuss the basis for these two contentions below.

On one hand, academic consulting can be research enhancing, opening new ideas and insights for research that could far outweigh the time and efforts devoted to problem solving activities committed by the scientists in consulting work. Following Azoulay et al. (2009) in their discussion on the potential complementarities between patenting and publishing, it is possible to argue along similar lines with regards to the potential complementarities between academic consulting and publishing. In this sense, academic consulting can reinforce the research activities of the academic scientists for the following reasons. First, consulting activities may be direct by-products of research activities, as in the cases in which joint research activities require the active assistance of academics to industrialists’ requirements (Mansfield, 1995; Thursby et al., 2001). Second, academic consulting may be an additional source of funding for the laboratory or department of the consulting scientist and contribute to the research agenda of the university department. Third, academic 
consulting might help making acquaintances with researchers in companies, making the academic scientist visible to new constituencies and intertwine with new research networks that might become sources of ideas for new research projects (Azoulay et al., 2009).

This latter type of consulting would fit the 'research-driven' mode suggested by Perkmann and Walsh (2008), which is generally characterized by medium to long-term commitments between the academic scientists and their clients, and would generally involve access to data drawn from industrial processes or information on problems and challenges from large, science and technologyintensive firms.

On the other hand, much of the discussion on academic consulting rests on the perception that time spent on consulting detracts from dedication to the primary roles of teaching and research (Mitchell and Rebne, 1995). In this sense, it is argued that there is a trade-off between consulting and research activities because devoting time to consulting comes at the expense of efforts oriented to basic research. This rationale is congruent with one type of consulting that has been suggested by Perkmann and Walsh (2008): ‘opportunity-driven’ consulting. According to Perkmann and Walsh, opportunity-drive consulting is mainly articulated as a form of income augmentation on the side of the academic scientist, who is basically motivated into consulting as a response to personal income opportunities. This type of academic consulting is further characterized by the mobilization of already existing expertise by the scientists involved in consulting, and a low level of commitment with regards to the interaction with the client (i.e. short term contracts). The rationale here is that, while these contractual arrangements can provide additional sources of personal income for the scientists, these contracts are not necessarily complementary with academic research, and may actually be counterproductive if they detract a significant amount of time from research activities.

Finally, the literature has suggested a number of factors that provide further structure to the relationship between academic consulting and scientific productivity. One such factor relates to the moderating role of the field of science. In certain scientific fields academic consulting might be particularly well-aligned with academic research agendas, compared to other fields. For instance, in engineering-related fields of science, academic consulting can be quite complementary with research activities insofar as it increases the exposure of scientists to new contexts of application of research and to areas of commercially useful inquiry that can spur insightful ideas for research. Conversely, in more fundamental fields of science, these complementarities might be less obvious or infrequent. Perkmann and Walsh (2008) suggest that much of the research-driven consulting is 
likely to be found in Pasteur-type fields of science, where considerations of fundamental understanding are combined with consideration of practical use in setting research agendas.

In short, even though academic consulting plays an important part as a mechanism of knowledge transfer, there is a paucity of research on this subject. Our work aims at filling this gap by investigating the relationship between scientists’ engagement in consulting activities and their research productivity.

\section{DATA SOURCES}

\subsection{Data}

The main source of information used in this investigation was provided by the Technology Transfer Offices (TTOs) of the five public universities of the Valencian Higher Education system: University of Alicante (UA), Miguel Hernández University (UMH), Jaume I University (UJI), University of Valencia (UV) and the Polytechnic University of Valencia (UPV). These five public universities account for more than $90 \%$ of the total faculty and students in the region, since private universities have a comparatively small size and cover a narrow range of academic disciplines.

The data are analysed at the individual faculty level. Our sample consists of 2678 research active faculty - that is, academics who have been recipients of publicly funded grants or principal investigators in R\&D contracts over the period 1999-2004. This figure accounts for approximately $40 \%$ of the entire population of faculty in these five universities in $2004 .{ }^{1}$ Our faculty sample is distributed across the five universities considered in this study, as follows: $43 \%$ at UV; $24 \%$ UPV; 15\% UA; 9\% UJI; and 9\% UMH (a distribution that is largely identical to that corresponding to the entire faculty population across the five universities).

One of the value added features of the data used in this study refers to its completeness (i.e. it covers information about all research contracts and projects in which university scientists have been involved) and its reliability (i.e. the information available refers to administrative data collected by university central services including full details on research projects and contracts). More specifically, the data provided by the five TTOs includes three types of information. First, it provides detailed information on the specific type of research projects and contracts in which academic researchers have been involved over the period 1999-2004. This includes project level

\footnotetext{
${ }^{1}$ Figures refer to full-time employed faculty and were obtained from Instituto Valenciano de Estadistica (www.ive.es).
} 
information for both publicly funded research projects and contractual arrangements with thirdparties, either industry or public administration. One of the contractual arrangements for which this data provides detail information is academic consulting, including the precise number and volume of monetary income of the consulting contracts in which researchers are engaged. It is critical to point out that faculty reporting on the sources of funding linked to their academic activity, is mandatory in the Spanish Higher Education system. ${ }^{2}$ Therefore, this dataset is liable to be a very accurate and comprehensive source of information regarding all contractual arrangements and research projects in which academics have been involved. Second, the database also provides information on various individual characteristics of faculty, such as: work experience, academic status and academic discipline. As in the case of funding sources, central services at universities keep records of the academic status and years of experience of each faculty employed at the university.

Finally, the database provides information on the total number of articles published by each researcher in journals indexed in the Thomson Institute of Scientific Information (ISI) for the period 2003 - 2004. As with the previous two types of information, University central services were responsible for conducting a thorough scrutiny of the number of articles published by researchers in the Thomson ISI database for this two-year period. The main drawback of this data, however, is that information about the identity of faculty remained confidential, and thus, further collection of data at the individual level, from secondary sources, was not viable in our case. ${ }^{3}$

\subsection{Academic consulting}

In order to fully understand the nature of our data on academic consulting, it is important to provide a brief overview on the regulation that governs the contractual arrangements that university researchers are allowed to establish with non-academic agents.

In the Spanish context, university-industry linkages are regulated by the Organic Law of Universities (LOU-2001, and specifically, Article 83). This regulation authorizes academic

\footnotetext{
${ }^{2}$ All funding resources obtained by faculty as a result of their research projects, R\&D contracts or consulting services, are automatically integrated to the university budget. After contractual arrangements are signed with the external funder, it is the university that authorises faculty to make use of the resources obtained. In this sense, all contractual arrangements are directly reported to the university central services and TTOs. Failing to report on contracting arrangements on the side of the faculty would be considered as illegal in the Spanish Higher Education System.

${ }^{3}$ This means that it is not possible for the authors of this study to collect additional information from secondary sources, at the individual level, to complement this data. We are uninformed about the identity of the faculty and therefore we cannot, for instance, gather information about citations received by papers from our sample of academics, or about the past track of publications of the faculty in our dataset.
} 
researchers to sign agreements with public or private organisations for the development of work of a scientific, technical or artistic nature, as well as for the development of specialisation courses or specific activities associated with training. In this sense, academics have the capacity to establish contractual arrangements with companies, and perform advisory and consulting agreements for them, provided that such contracts are established through the university - that is, through the organisational structures available at universities that have the mission to channelling knowledge and technology transfer activities.

Under this University Act, each university is autonomous in establishing procedures for authorisation of the work and monitoring consulting agreements, and to set the criteria to determine the destination of the assets and resources obtained through these agreements. In the case of the Polytechnic University of Valencia (UPV), for example, this university retains $10 \%$ of the total amount of funding from external agents in concept of overheads, while the rest of the stream of income from the contract covers the material costs involved in the development of the planned tasks and the remuneration of the academic scientist responsible for the implementation of the activities agreed in the contract. With regards to the remuneration of faculty involved in consulting activities, the income received must not exceed 1.5 times the annual salary that corresponds to the highest category of academic faculty - i.e. the category of full-time professor ${ }^{4}$.

Considering this legal framework as our point of reference, consulting activities are identified on the basis of well-defined tasks developed through contractual agreements. More specifically, the purpose of these contractual arrangements is generally an activity aimed at solving specific problems, which is not supposed to generate new scientific or technological knowledge, but can promote or facilitate technical and/or organisational innovation. In this type of contracts we find technical and professional work, including design, and technological support to industry. Consulting work also includes other type of tasks such as technical services (e.g. data analysis, testing) which are normally provided by universities through specialised equipment and skilled personnel available at research centres.

Drawing on the above characterisation of academic consulting, Table 1 and 2 show that academic consulting is a frequent contractual arrangement among university academics in the universities analysed in this paper. Indeed, as Table 1 shows, $49 \%$ of our sample of academic researchers has been involved at least once in academic consulting over the period 1999-2004. The proportion of

\footnotetext{
${ }^{4}$ UPV's Management Regulations for Research, Technology Transfer and Continuing Education, BOUPV 43, http://www.upv.es/entidades/SG/infoweb/sg/info/U0537298.pdf.
} 
scientists involved in academic consulting is generally higher than the proportion of scientists involved in R\&D contracts (with the only exception of University of Valencia). It is also interesting to note that there are significant differences by scientific discipline: scientists in engineering-related fields have a much higher propensity to engage in academic consulting - above $70 \%$ of scientists in Engineering engage in academic consulting over the six-year period analysed, compared to $40 \%$ for the cases of scientists who belong to the others scientific disciplines analysed (see Table 2).

[Insert Tables 1 and 2 in here]

\section{METHODS AND DESCRIPTIVE STATISTICS}

In order to investigate the relationship between academic consulting and scientific productivity we rely on several empirical approaches to check the robustness of our results. First, we rely on a standard regression framework where several estimation strategies are set forward (Section 4.1). Second, we present our preferred method: an average treatment effect on the treated (henceforth ATT) matching estimator (Rosenbaum \& Rubin, 1983). This two-step procedure has been chosen for the following reasons: a) regression analysis is a standard approach that can be legitimately used as a point of reference in terms of a base-line $\operatorname{model}^{5}$; b) the ATT matching estimator is a more appropriate method in our setting because it allows to conduct a quasi-experimental approach comparing a treated and a control group (thus reducing the selection bias arising from self-selection into treatment). The ATT method is a fully non-parametric approach and, for this reason, prevents misspecification error due to ex-ante assumptions of the functional form in the outcome equation (Caliendo \& Kopeinig, 2008). In particular, we assimilate academic consulting to a treatment conducted on a scientist that, once received, may influence his future rate of research productivity (Section 4.2).

\subsection{Regression framework}

As discussed in Section 2.2, we are interested in examining the relationship between engagement in consulting activities and scientific productivity. We investigate this relationship through the estimation of the following econometric model for the sample comprising full information for 2402 scientists:

\footnotetext{
${ }^{5}$ We are grateful to the editor for pointing this out.
} 


\section{Equation 1}

NumberPub $_{i}=\beta_{1}$ DAcademicConsulting $_{i}+\beta_{2}$ QualityDpt $_{i}+\beta_{3}$ Re searchAbility $_{i}+\beta_{4}$ Focus $_{i}+$ $+\beta_{5}$ CompetitiveRD $_{i}+\beta_{6}\left(\text { CompetitiveRD }_{i}\right)^{2}+\beta_{7}$ ContractRD $_{i}+\beta_{8}\left(\text { ContractRD }_{i}\right)^{2}$ $+\beta_{9}$ Experience $_{i}+\beta_{10}\left(\text { Experience }_{i}\right)^{2}+\delta^{T} Z_{i}+\varepsilon_{i}$

Where NumberPub $b_{i}$ is the number of ISI-publications published in the period 2003-2004, $Z_{i}$ indicates a series of scientist specific control variables; and $\varepsilon_{\mathrm{i}}$ is the error term.

Our main independent variable is the engagement in consulting activity, which we measure with a dummy variable equal to 1 if the academic scientist $i$ engaged in academic consulting in the 19992002 and zero otherwise (DAcademicConsulting ${ }_{i}$ ). In an alternative version of the model we use, instead of a dichotomous variable, an ordered variable to check the relationship between scientific productivity and different levels of engagement in consulting activity (VConsulting). VConsulting is an ordered variable taking on three different values according to the amount of monetary income that scientist $i$ gets from consulting activity over the period 1999-2002. ${ }^{6}$

Other explanatory variables are introduced to capture alternative explanatory factors of research performance (Azoulay et al., 2009; Hottenrott \& Thorwarth, 2011): a) funding sources; b) academic status of the researcher and c) research ability of the scientist. The choice of these variables was also driven by the need to satisfy the conditions for a robust estimate of the ATT (as we explain in Section 4.2).

Competitive $R D_{i}$ is the average number of research projects funded by local, national or European public bodies in the 1999-2002 period, awarded on the basis of a peer-review evaluation of the competing proposals submitted by scientists. ContractRD $D_{i}$ is the average number of research contracts funded by private companies or public administrations in the 1999-2002 period, which generally involve well-specified goals and targets set by the funding agencies. Experience $_{i}$ is a proxy for work experience and is measured as the number of quinquenios ${ }^{7}$ obtained by the scientist. We have also controlled for the effect stemming from the academic position of the scientist by

\footnotetext{
${ }^{6}$ It takes the following values: 0 (scientist did not carry out any consulting activity), 1(the amount of monetary income from consulting contracts is lower than the median value) and 2 (the amount of monetary income from consulting contracts is higher than the median value)

${ }^{7}$ In Spain, the quinquenio (literally a five-year period) is a form of recognition almost automatically granted to academic scientists based on their experience, which positively affects their salaries. Quinquenios are granted every five years, following an evaluation process. Thus, a professor who has been in a university for 20 years could possess up to 4 quinquenios and therefore the number of quinquenios can be used as a proxy for academic experience.
} 
including a set of academic position dummies. In order to control for the presence of a curvilinear effect in the funding of research as well as in the level of experience we also include the squared value of the last three variables: $\left(\text { Competitive } R D_{i}\right)^{2},\left(\text { ContractRD }_{i}\right)^{2}$ and $\left(\text { Experience }_{i}\right)^{2}$.

More importantly, in an attempt to control for the presence of an omitted variable bias arising from unobserved heterogeneity at the individual level, we have considered three variables that measure important dimensions of scientists’ unobservable attributes: (i) individual research ability; (ii) whether the scientist is able to balance private and public research funding; and (iii) the quality of the research group in which scientists are working in.

As for the first measure, we have collected information on the number of 'sexenios' awarded to researchers over their academic careers. The 'sexenio' is a research recognition awarded to those faculty who succeed to demonstrate an outstanding research performance over a period of 6 years. With this information we computed the number of Sexenios awarded to an individual (relative to the number of years in academy) as a measure of the 'research ability' of the faculty in our sample (ResearchAbility $)$.

Second, we captured the balance between basic and applied research conducted by our sample of faculty, by examining the ratio between the number of R\&D contracts versus total number of research projects in which the individual has been involved in the period 1999-2002 (Focus F $_{\text {). This }}$ is a variable that ranges between 0 and 1: the close to 1 , the stronger the focus of research on meeting societal demands and having an applied nature (as opposed to more curiosity driven research). The rationale to consider this attribute lies in the contention that faculty with a higher balance between contract and competitive funding may be particularly well positioned to engage in consulting: in other words, keeping a good balance between proximity to the societal needs and capacity to conduct curiosity driven research. For instance, too high a proportion of Contract R\&D may crowd out the faculty capacity to engage in consulting activities.

Thirdly, we accounted for the research quality of the school (department) where faculty were affiliated to, since we have information from our original records about the name of the university and department where the researchers in our sample were employed in the period of the study. We collected information from ISI-Web of knowledge database, mainly number of scientific articles published and citations received in the period of reference, and computed a weighted indicator of 'research quality’ at the department level $\left(Q u a l i t y D p t_{i}\right)$. In particular, we follow Waltman et al 
(2011) and use the Mean Normalized Citation Score (MNCS) indicator. MNCS is defined as:

$\frac{1}{n} \sum_{i=1}^{n} \frac{c_{i}}{\theta_{i}}$ where $c_{i}$ denotes the number of citations of publication $i, e_{i}$ denotes the average number of

citations of all publications published in the same field and year as publication $i$. The resulting indicator takes on values that are greater or equal to zero. A value of one in the indicator means that the scientific impact of the department is as high as the average scientific impact worldwide (taking into account the publications in the same discipline and published in the same year); while values greater than 1 indicate that the scientific impact of the department is higher than the average worldwide scientific impact for the same discipline and year.

We have controlled for the effects stemming from the scientific field (DScientificField $)_{i}$ ) and

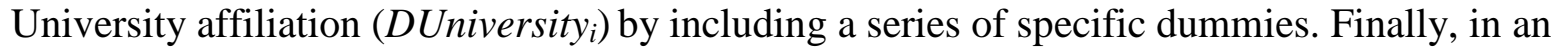
attempt to control as much as we can for unobserved heterogeneity, we also included a full set of interaction terms (ExperienceXScientificField; ExperienceXPosition and UniversityXPositionXScientificField).

Several estimation strategies are proposed for testing the robustness of the econometric model presented above. First of all, as baseline reference, we estimate the model via ordinary least squares. After that, given the count nature of our dependent variable (number of publications), we rely on a Poisson specification estimated via quasi- maximum likelihood (Gourieroux, et al., 1984). Finally, to account for the relative high number of zeros in the number of scientific articles published by the scientists contained in our sample, we estimate a zero inflated poisson model (Cameron \& Trivedi, 1998).

\subsection{ATT matching estimator}

Our second step to evaluate the effect of academic consulting on scientific productivity is an average treatment effect on the treated (henceforth ATT) matching estimator (Rosenbaum \& Rubin, 1983). In particular, we assimilate academic consulting to a treatment conducted on a scientist that, once received, may influence his future rate of research productivity. Operationally, treatment variable $D$ takes value 1 if an academic scientist has engaged at least in one consulting contract and 0 otherwise.

The fundamental problem is to measure how much the scientific production of scientists is affected by carrying out consulting activities. Formally: 
Equation 2

$$
E\left[Y_{1}-Y_{0} \mid D=1\right]=E\left[Y_{1} \mid D=1\right]-E\left[Y_{0} \mid D=1\right]
$$

where $E\left[Y_{1} \mid D=1\right]$ is the average scientific productivity of those scientists conducting consulting activity while $E\left[Y_{0} \mid D=1\right]$ is the average scientific productivity we would have observed for the same scientists had they not conducted consulting activity. Evidently, the second quantity is not observable in practice and it should be approximated. Under the conditional independence assumption, the matching estimator constructs a correct sample counterpart for those scientists that conducted consulting activity, had they not done it, by pairing each treated scientist with scientists of a comparison group and in this way, one is able to correctly estimate the ATT by the following equation:

\section{Equation 3}

$E\{E[Y \mid D=1, X=x]-E[Y \mid D=0, X=x] \mid D=1\}$

Rosenbaum and Rubin (1983) show that this is equivalent to estimate the difference:

\section{Equation 4}

$E\{E[Y \mid D=1, p(x)=\eta]-E[Y \mid D=0, p(x)=\eta] \mid D=1\}$

with $p(x)=P(D=1 \mid X=x) \cdot p(x)$ is the propensity score and is approximated via the estimate of a logistic model containing all the relevant covariates explaining the propensity to take the treatment. In our case, the $X s$ are a set of characteristics influencing the decision to engage in academic consulting.

The assumption of conditional independence turns out to be very important to consistently estimate the parameter of interest, i.e. the effect of consulting activity on the number of scientific publications of academic scientists. ${ }^{8}$ Unfortunately, by definition, the conditional independence assumption cannot be directly tested but the availability of ample information is important to define a vector of explanatory variables that makes the assumption as plausible as possible. Theory,

\footnotetext{
${ }^{8}$ Conditional independence is not the only assumption needed to consistently estimate the ATT but it is the one that is most difficult to satisfy. Other conditions to be satisfied are the stable unit treatment value assumption and common support. (Please, state clearly what are the other conditions: "Other two conditions to be satisfied are "the stable treatment value” and "the common support” assumptions (???)”.
} 
institutional set-up as well as previous literature are all things that can guide the correct choice of the variables used in the calculation of the propensity score and, in this way, can make more reliable the assumption of conditional independence.

The first step of our identification strategy is to estimate the following logistic model for the sample comprising full information for 2402 scientists:

\section{Equation 5}

DAcademicConsulting $_{i}=\alpha+\beta_{2}$ QualityDpt $_{i}+\beta_{3}$ Re searchAbility $_{i}+\beta_{4}$ Focus $_{i}+$ $+\beta_{5}$ CompetitiveRD $_{i}+\beta_{6}\left(\text { CompetitiveRD }_{i}\right)^{2}+\beta_{7}$ ContractRD $_{i}+\beta_{8}\left({\text { Contract } R D_{i}}\right)^{2}$

$+\beta_{9}$ Experience $_{i}+\beta_{10}\left(\text { Experience }_{i}\right)^{2}+\delta^{T} Z_{i}+\varepsilon_{i}$

where the definition of variables is the same as in Equation 1.

As noted in the above paragraph, the choice of the model used for the calculation of the propensity score is essential in order to credibly defend the conditional independence assumption. For this reason, the choice of the independent variables to include in the model has gone through accurate scrutiny. In particular, we relied on the former literature dealing with the determinants of academic consulting at the individual level. Extant literature agrees on what the most important drivers of academic consulting are: (i) the amount of research funding from industry (Boardman \& Ponomariov, 2009; Landry et al., 2010); (ii) the amount of government research funding (Gulbrandsen \& Smeby, 2005; Jensen et al., 2010); (iii) experience of the academic scientist (Link et al., 2007); (iv) size and orientation to applied research of the University the scientist is affiliated to (Arvanitis et al., 2008; Bekkers \& Bodas Freitas, 2008; Landry, 2010) and (v) working in scientific fields particularly oriented to applied research, such as engineering and technology (Gulbrandsen \& Smeby, 2005; Arvanitis et al., 2008; Bekkers \& Bodas Freitas, 2008; Boardman \& Ponomariov, 2009; Grimpe \& Fier, 2009).

The second step in our identification strategy is to use the estimated propensity score $(p(x))^{9}$ to match the group of scientists engaging in academic consulting with the most similar group of

\footnotetext{
${ }^{9}$ The propensity score has been also calculated by adopting two alternative specifications where all of the covariates are pre-determined with respect to the treatment. In first alternative specification, the propensity to engage in academic consulting is defined in the 2001-2002 period while the covariates are defined in the 1999-2000 period. In the second specification, the propensity to engage in academic consulting is defined in the 2000-2002 period while the covariates
} 
scientists not engaging in academic consulting which is equivalent to compute the empirical counterpart of equation 3 and provides an estimate of the ATT:

\section{Equation 6}

$A T T=\frac{\sum_{i \in T}\left(\text { NumberPub }_{i}-\sum_{j \in M(i)} w_{i j} \text { NumberPub }_{j}\right)}{N T}$

where $N u m b e r P u b_{i}$ and NumberPub $b_{j}$ are the number of ISI-publications published respectively by scientists engaging in academic consulting and scientists not engaging in academic consulting in the 2003-2004 period; $T$ is the set of scientists engaging in academic consulting; NT is the set of scientists not engaging in academic consulting; $M(i)$ is the matching set for unit $i$ and represents the set of control scientists we choose to match with each scientist engaging in academic consulting; $w_{i j}$ are the weights assigned to the different units $j$ which represent scientists not engaging in academic consulting. Different methods are available that choose differently $M(i)$ and $w_{i j}$. We implement three of the most popular ones in our estimation of the ATT - i.e. nearest neighbour matching, radius matching and kernel-based matching - thus providing a robustness check of the results obtained (Caliendo \& Kopeinig, 2008). ${ }^{10}$

In addition to the estimation of the overall effect of consulting on the productivity of academic scientists, we estimate the effect of consulting on productivity across the different scientific fields. In this case, we calculate the ATT after matching treated and controls in the same scientific field by the value of the propensity score. We do this by using the three different matching algorithms mentioned above. In this way, we are able to investigate the effect of academic consulting on the scientific productivity for scientists belonging to different scientific fields.

Traditionally the propensity score matching approach has been applied to single-treatment frameworks. Arguably, however, in the case of the effect of consulting on the productivity of academic scientists it is not only whether a scientist conducts consulting, but how much consulting a scientist is doing that may matter. Our definition of consulting as a treatment on the academic

are defined for the year 1999. Results are in line with those provided in the following and they are available from the authors upon request.

${ }^{10}$ In the nearest neighbour matching, a treated unit is matched to a set of units in the control group that is closest in terms of the Mahalanobis distance between the respective propensity scores. In the radius matching, the matching is done using a tolerance level on the maximum propensity score distance between nearest neighbours (caliper). In this way, not only the closest neighbour within a pre-determined distance is matched, but all the individuals in the control group within the caliper are matched together. In the Kernel-based matching, a treated unit is matched to all non-treated units in the control group, but the controls are weighted according to the Mahalanobis distance between the treated unit and each non-treated unit. 
scientist forces us to measure it as a binary variable only (doing consulting or not doing it).

However, providing a measure of the intensity of consulting activity at the individual scientist level would allow us to investigate some of the theoretical hypotheses proposed by the existing literature, related to the existence of a curvilinear relationship between consulting and scientific productivity.

The optimal solution would be to consider a continuous treatment that is equal to the number of consulting contracts obtained by each single scientist. However, the number of consulting contracts is not a continuous variable but a count variable. To cope with the count nature of our treatment variable, we rely on the approach pioneered by Imbens (2000) and Lechner (2001) who take into consideration estimation of ATT under multiple treatments. Operationally, we take into account the amount of the monetary income from consulting activity obtained by the academic scientists contained in our sample by grouping the amount over the period 1999-2002 into predefined groups. In particular, three different intensities of treatment are taken into consideration: (i) "high” (scientists reporting an amount of monetary income from consulting contracts above the median value), (ii) “medium” (scientists reporting an amount below the median value) and (iii) “zero” (those reporting no consulting contracts).

To provide evidence on the role played by different levels of engagement in consulting activity on the scientific productivity of the scientists contained in our sample, we follow Moffitt (2008) and Xie et al. (2012) and we evaluate heterogeneity in treatment effects. ${ }^{11}$ We do this by estimating a locally weighted regression of the matched differences for treatment on the treated (computed with propensity score matching via kernel method) on the propensity score.

\subsection{Descriptive statistics of key variables}

A description of the variables used in our analysis is presented in Table 3. Table 4 presents the basic statistics for the variables in the regression analysis, and their correlation coefficients. As shown in Table 4, the mean of ISI journal publications per researcher is 6 . However, this variable is characterized by a highly skewed distribution and a significant over-dispersion. In fact, $43 \%$ of academics did not publish during the two-year period 2003-2004, and 20\% of them generated $80 \%$ of the publications. Regarding knowledge transfer activities, Table 4 shows that $36 \%$ of academics in the sample have carried out consulting activities over the period 1999-2002, compared to 24\% of academics who have participated in R\&D contracts over the same time period (i.e. 1999-2002).

\footnotetext{
${ }^{11}$ We are particularly grateful to one anonymous reviewer for pointing this out.
} 
In order to conduct a preliminary analysis of the effect of consulting activities on the scientific production of academics, we carried out a $t$-test for comparison of means for two groups of scientists: those who conducted consulting activities over the period 1999-2002 versus those who did not. The results show that there is a statistical significant difference between the two groups of scientists. Specifically scientists who did not engage in consulting activities exhibit a statistically significant higher scientific output (Table 5).

[Insert Tables 3, 4 and 5 in here]

\section{FINDINGS}

The results of the econometric analysis are illustrated in Tables 6, 7, 8, 9, and 10.

As for the regression framework, Table 6 where the dependent variable measures the number of publications at the scientist level contains the results from the different models proposed in section 4.1. CompetitiveRD and Experience exhibit positive coefficients, significant at the standard confidence levels, meaning that both positively contribute to explain scientific productivity. More importantly for the present study, DAcademicConsulting always exhibits a negative and significant coefficient across all the different methods of estimation meaning that engagement in academic consulting has a detrimental effect on scientific productivity. Furthermore, in line with our expectations, ResearchAbility contributes to explain scientific productivity as evidenced by significant and positive coefficients. Overall, these results are robust across all different models even when we control for non-linearity and the count nature of the dependent variable (through the Poisson specification) or we control for the high number of zeros characterising our dependent variable (through the zero inflated poisson model). ${ }^{12}$

Even more interesting results are obtained when the amount of monetary income stemming from consulting activity is taken into consideration. Columns 2a, 2b and 2c of Table 6 report the results for the three models above with the only difference of substituting the explanatory variable DAcademicConsulting with VConsulting. The results point to a more nuanced relationship between scientific productivity and consulting activity, showing distinct effects at different degrees of

\footnotetext{
${ }^{12}$ Further robustness checks have been implemented and refer to two separate issues. First, we controlled whether the estimated coefficients are biased due to a problem of overdispersion (conditional expected value of the number of publications is relatively far away from its conditional variance). To control for that, we run negative binomial regression and zero inflated negative binomial model. All different specifications provide similar results with a negative and highly significant coefficient for the engagement in academic consulting. The results are available from the authors upon request.
} 
involvement in consulting. When the amount of monetary income from consulting is at a medium level (below the median value) no significant relationship exists between scientific productivity and consulting; it is only for a high degree of involvement (i.e. when the amount of monetary income from consulting contracts is above the median value) that a negative and significant relation becomes apparent.

\section{[Insert Table 6 in here]}

As for the ATT matching estimator, Table 7 presents the estimates of the logistic model used to compute the propensity score. Table 8 reports the ATT of consulting on the scientific productivity of academic scientists. Table 9 reports the ATT of academic consulting on the scientific productivity of scientists matched according to their value of the propensity score and their scientific field. Table 10 illustrates the ATT for the intensity of consulting on the scientific productivity of academic scientists both in general and across the different scientific fields. Tables 8 and 9 report the results for three different matching algorithms (nearest neighbour method, kernelbased method and radius method). In the same tables, following Caliendo and Koepeing (2008), we report a series of indicators assessing the matching quality of the procedure adopted.

Let us first consider the results shown in Table 7 where the dependent variable captures the propensity to engage in consulting activities at the scientist-level (DAcademicConsulting ${ }_{i}$ ). Quite interestingly, both ResearchAbility and Focus are found to be significant and negative at the 1\% confidence level, thus pointing out a negative selection into consulting of scientists with lower innate ability and a lower capacity to balance competitive grants for research and industry funded research. Competitive $R D_{i}$ exhibits negative coefficient, significant at the $1 \%$ confidence level meaning that academic scientists are less likely to engage in consulting activities if they obtain more research projects. This result points to the existence of a negative relationship between the ability or willingness of a scientist to obtain funding for research through competitive research projects and consulting. Moreover, the amount of research projects impact in a non-linear way the propensity to engage in consulting activity as evidenced by the positive and significant coefficient of CompetitiveRD $D_{i}^{2}$. ContractRD $D_{i}$ exhibits a positive coefficient, significant at the $1 \%$ confidence level meaning that academic scientists are more likely to engage in consulting activities if they receive more research contracts from industry and public administrations. It is interesting to note that the amount of research contracts funded by industry and public administrations impact in a non-linear way the propensity to engage in consulting activity. Indeed, the coefficient of 
Contract $R D_{i}^{2}$ is negative and statistically significant at the $5 \%$ confidence level. This suggests that the contribution of an additional research contract to the probability of engaging in academic consulting decreases with the number of contracts obtained. In the same vein, the positive and significant (at 1\%) coefficient of $\operatorname{Exp}_{i}$ implies that the level of experience gained by the scientist plays a role in explaining the propensity to engage in academic consulting. As before, the squared term $\operatorname{Exp}_{i}^{2}$ is negative and significant at the 1\% confidence level pointing out that a non-linear relationship is likely to be present even in this case.

It is worth mentioning how all of the above results are in line with those obtained by the extant literature. This is an important preliminary result reinforcing our belief that the conditional independence assumption is a reliable identifying assumption given our theoretical set-up and the results obtained by the previous literature.

\section{[Insert Table 7 in here]}

Let us now focus on the results of the ATT matching estimators where the outcome variable is always the number of ISI publications published in the 2003-2004 period (NumberPub ${ }_{i}$ ). Table 8 reports the ATT of consulting on the scientific productivity of academic scientists following the three matching algorithms described in the previous section. ${ }^{13}$ In all of the three cases the effect of consulting on scientific productivity of academic scientists is negative and significant at the usual confidence levels. In particular, engaging in consulting activity implies less ISI-publications in the following period, with the amount of neglected publications ranging, on average, between 1.46 and 1.81 (depending on the matching algorithm used). Table 9 reports the ATT of consulting on the scientific productivity of academic scientists across the different scientific fields. ${ }^{14}$ The ATT of academic consulting is found to be negative and significant in the fields of "Natural and exact sciences” and "Engineering”. In the former case, engaging in consulting activity implies less ISIpublications in the following period, with the amount of neglected publications ranging, on average, between 1.49 and 2.29. In the latter, the amount of neglected publications ranges, on average, between 2.9 and 3.54. In the other scientific fields (i.e. "Medical sciences" and "Social sciences and humanities”), the ATT is not found to be significant at the usual confidence levels.

\footnotetext{
${ }^{13}$ In addition to the findings presented here and to further check the reliability of the results, we also carried out 1-to-1 matching and covariate matching (Abadie \& Imbens, 2002). In both cases, we find similar results to the ones presented here. These results are available from the authors upon request.

${ }^{14}$ Due to the low number of scientists belonging to "medical sciences" in our sample, we have decided to not report results for this scientific field.
} 
[Insert Tables 8 and 9 in here]

The result of the negative effect for the field of "Engineering and technology" is somewhat counterintuitive given that the extant literature found proximity between university and industry in applied sciences such as engineering to exert a positive effect on the productivity of the academic scientist (Calderini et al., 2009). Nevertheless, by taking into consideration the intensity of treatment we are able to better portray the relationship between consulting and scientific productivity across different scientific fields. Table 10 illustrates the results of the estimation of multiple treatment effect for overall consulting and different scientific fields. In the case of overall consulting, a negative effect on the productivity of academic scientists is found when the amount of consulting carried out is high. In this case, the neglected publications are, on average, 2.89 ("high vs. zero"). In the same vein, when the ATT for the different scientific fields is taken into consideration, a negative and statistically significant effect is found only when the level of consulting is high ("high vs. zero"). The effect in terms of neglected publications is 4.12 for scientists working in the field of "Natural and exact sciences", 0.45 for those in "Social Sciences and Humanities" and 4.03 for those in "Engineering and technology". ${ }^{15}$ When the level of consulting is moderate, no statistically significant effect is found across the different disciplines.

\section{[Insert Table 10 in here]}

In line with the effort to analyse how scientific productivity changes along the intensity of engagement in consulting, we also report the graphical results (see Figures 1 and 2) of the analysis carried out that investigates the heterogeneity of the treatment effects. Figure 1 shows the results for the overall sample plotting the matched differences for the ATT at the different levels of the propensity score. Moving along the horizontal axis implies an increase in the engagement in consulting of the scientists contained in our sample. It is clear from the negative slope in the figure that an increasing negative effect is present and that this effect is more significant for higher level of engagement. Figure 2 shows similar results but for the three scientific fields considered in the analysis. In line with the results obtained from the previous analysis, "Natural and Exact Sciences” and "Engineering” fields present negative and significant effect for high level of engagement in consulting while "Social sciences and humanities" present a slightly negative but not significant effect.

[Insert Figures 1 and 2 in here]

\footnotetext{
${ }^{15}$ As before, we do not report results for the group of scientists belonging to "medical sciences” due to the small sample
} size. 
Finally, it is interesting to note that we assessed the quality of all the matching procedures carried out along our work. In particular, Tables 8, 9 and 10 report the Mc Fadden's Pseudo $\mathrm{R}^{2}$ of running the same logits with the overall sample (Pseudo $\mathrm{R}^{2}$ before) and only with the matched sample (Pseudo $\mathrm{R}^{2}$ after). In addition, we report whether all t-tests for the equality of means in the treated and non-treated groups cannot be rejected at the 5\% significance level after matching. Finally, the mean absolute standardised bias before and after matching is reported. These tests confirm the robustness of the method used. First, the Pseudo $\mathrm{R}^{2}$ of running the same logits with only the matched sample is always considerably lower. Second, in all cases the t-tests for the equality of means in the treated and non-treated groups cannot be rejected at the $5 \%$ significance level after matching. Finally, we find that the bias reduction after matching is always considerable.

\section{CONCLUSIONS}

The effect of consulting on the productivity of academic scientists has, up to now, received scant scholarly attention. Indeed, the extant literature has mainly concentrated on the impact of more formal channels of knowledge and technology transfer (such as patenting and spin-offs) on the scientific productivity of scientists, providing mixed findings that reflect different views in an ongoing open debate.

This paper provides preliminary evidence for the impact of consulting activity on the scientific productivity of academics. Taking advantage of a unique dataset containing detailed information on the activities carried out by scientists employed in five universities located in a Spanish region (i.e. Valencia Region), and using both a regression framework and a propensity score matching estimator method, we find, on the whole, a negative relationship between consulting and the productivity of academic scientists. More specifically, we find that the negative effect of conducting consulting activities can be quantified in the order of magnitude of 1.4 to 1.8 publications in a subsequent two-year period (2003-2004).

However, if we look at each of the scientific disciplines separately and the intensity of consulting activity is taken into consideration, the negative effect is found to hold only when the level of consulting activity is high: that is, when scientists obtain an above the median amount of monetary income from consulting activity over a 4 year period (in this case, 1999-2002). Conversely, when 
scientists engage moderately in consulting activities (the amount of monetary income is below the median over the same 4 year period), no significant effect on scientific productivity is found.

Overall, we can interpret these results along the line of the arguments raised by the scarce theoretical literature dealing with the topic (Mitchell and Rebne, 1995; Perkmann and Walsh, 2008): time spent on consulting might detract from dedication to the primary role of research, and thus negatively affect publication performance. In particular, a trade-off between consulting and research activities is likely to arise when devoting time to consulting comes at the expense of efforts oriented to research. This can be the result of what Perkmann and Walsh (2008) call 'opportunitydriven' consulting. According to these authors, opportunity-driven consulting is a type of consulting that provides additional sources of personal income for the scientists but it may be counterproductive for research performance if detracts a significant amount of time from research activities.

Our findings contribute to this literature by showing that this trade-off between consulting and research performance only sets in for very high levels of engagement in consulting activities. While moderate levels of engagement in consulting activities have no significant effect on the scientists' research performance. We consistently find this non-linear effect in the scientific fields of "Natural and exact sciences” and "Engineering and technology”.

Though this is an important result, we believe it is too premature at this stage to derive implications in terms of the 'optimal' level of investment in consulting activities for scientists. As we explain below, more information is requested to run more articulated analyses accounting for other factors that might have a role in explaining the involvement in consulting activities by scientists and their publication productivity.

Overall our results pave the way for future research on the impact of consulting activities on scientists' academic productivity. Specifically we think that more accurate studies addressing the impact of consulting activities on scientists' academic productivity should take into account additional information with regards to: a) the consulting activity itself, b) the academic scientists and c) the diverse institutional settings.

As for the consulting activities, it would be desirable to account for the nature or type of consulting and its actual content to analyse the extent to which consulting activities are in line with scientists' 
interests and the extent to which they offer insights for new research contributions. Moreover, on top of the number of, and monetary income from, consulting activities, it would be appropriate also to account for their length and the number of individuals and non-academic organisations involved, among other features.

With regard to scientists, a major limitation of the approach pursued in this paper is that it requires us to rely on the conditional independence assumption. Although we try to convince the reader that we controlled for all critical covariates driving the decision to engage in consulting activity, we are not able to check whether an endogeneity problem still persists. Indeed, the selection into treatment (the decision to engage in consulting) is the outcome of a deliberate choice by the scientists. For instance, low productive individuals may be discouraged from further pursuing scientific activity and find consulting appealing in terms of personal income increase; on the contrary, more productive scientists may actually find it more rewarding to conduct research (at least from an intellectual point of view) rather than engaging in consulting. In this case, consulting would occur along with a decrease in publication activity, but would not explain the latter. While we have attempted to capture scientists’ research ability, more accurate measures of past research performance should be taken into account in future research.

In order to address these endogeneity problems it would be also crucial to account for the heterogeneity of the institutional settings where scientists conduct their research activities. The action of being involved in consulting activities can be explained by individuals' intention to perform a given behavior, which is both influenced by individual level characteristics and by the environment in which scientists operate, in accordance to intention-based models (Ajzen, 1991; Krueger et al., 2000). It is reasonable to think that the latter, which accounts, among other things, for universities' polices and for the type of support that they offer to technology transfer in general, influence the individual intention to get involved in consulting activities. Indeed, it is important to acknowledge that country-level regulation linked to academic consulting is a critical factor to account for, in order to claim for any generalizability of the results presented in this paper. Indeed, different regulatory and incentive structures may lead to different results: it is likely that the institutional regulations characterising the Spanish case might influence the engagement in consulting differently compared to other countries, such as US. Whether the degree of engagement in consulting activities in countries like US is higher than in Spain (or other European countries with similar characteristics), however, remains an open question for empirical investigation. 
Finally, although we find that our main results are confirmed by several additional robustness checks, the lack of a pure experimental setting - which would lead to a more conclusive analysis warrants some caution in the causal interpretation of our results. It is possible that our results might be driven by unobserved factors not appropriately controlled for. The evidence we have is suggestive in that scientists with particularly high levels of consulting activity appear to be robustly less productive in terms of papers published (as compared to scientists who do not engage or have a moderate level of engagement in consulting). As the first study of its kind to provide evidence on the relationship between academic consulting and scientific productivity, we believe these results represent an important contribution to the literature and should help guiding further research on this topic. Future work should try to address the points mentioned above to extend our results. In spite of these limitations, we believe that the insights gained from our study will serve as a guide and foundation for future work aimed at investigating the effect of academic consulting on scientific productivity. 


\section{REFERENCES}

Abadie, A. \& Imbens, G. (2002), 'Simple and bias-corrected matching estimators for average treatment effects', Technical report n. 283, NBER, National Bureau of Economic Research Cambridge, Mass., USA.

Agrawal, A. and Henderson, R. (2002). Putting Patents in Context: Exploring Knowledge Transfer from MIT, Management Science 48(1): 44-60.

Arvanitis, S.; Kubli, U. \& Woerter, M. (2008), 'University-industry knowledge and technology transfer in Switzerland: What university scientists think about co-operation with private enterprises', Research Policy 37(10), 1865-1883.

Azoulay, P.; Ding, W. \& Stuart, T. (2009), 'The Impact Of Academic Patenting On The Rate, Quality And Direction Of (public) Research Output', Journal of Industrial Economics 57(4), 637676.

Bekkers, R. \& Freitas, I. M. B. (2008), 'Analysing knowledge transfer channels between universities and industry: To what degree do sectors also matter?', Research Policy 37(10), 18371853.

Blumenthal, D., Campbell. E., Anderson, M., Causino, N., and Seashore-Louis, K. (1996). Participation of life-science faculty in research relationships with industry, New England Journal of Medicine 335: 1734-1739.

Boyer, C.W., Lewis, D.R. (1984). 'Faculty consulting: responsibility or promiscuity?' The Journal of Higher Education 55 (5): 637-659

Breschi, S., Lissoni, F. \& Montobbio, F. (2008), 'University patenting and scientific productivity: a quantitative study of Italian academic inventors', European Management Review 5: 91-109.

Breschi, S., Lissoni, S., and Montobbio, F. (2007). The scientific productivity of academic inventors: New evidence from Italian data, Economics of Innovation and new Technology 16(2): 101-118.

Buenstorf, G. (2009), 'Is commercialization good or bad for science? Individual-level evidence from the Max Planck Society', Research Policy 38, 281-292.

Calderini, M.; Franzoni, C. \& Vezzulli, A. (2009), 'The unequal benefits of academic patenting for science and engineering research', Engineering Management, IEEE Transactions on 56(1), 1630 .

Caliendo, M. and Kopeinig, S. (2008), Some practical guidance for the implementation of propensity score matching, Journal of Economic Surveys, 22(1): 31-72

Cameron, A. \& Trivedi, P. (1998), Regression analysis of count data, Vol. 30, Cambridge University Press.

Campbell, E.G., Clarridge, B.R., Gokhale, M., Birenbaum, L., Hilgartner, S., Holtzman, N.A. and Blumenthal, D. (2002). 'Data withholding in academic genetics: evidence from a national survey’, Journal of American Medical Association, 287 (4): 473-480.

Cohen, W. M.; Nelson, R. R. \& Walsh, J. P. (2002), 'Links and Impacts: The Influence of Public Research on Industrial R\&D', Management Science 48(1), 1-23.

Boardman \& Ponomariov (2009), 'University researchers working with private companies', Technovation 29(2), 142-153.

Crespi, G., D’Este, P., Fontana, R. \& Geuna, A. (2011), 'The impact of academic patenting on university research and its transfer’ Research Policy 40 (1): 55-68. 
D'Este, P. \& Patel, P. (2007), 'University--industry linkages in the UK: What are the factors underlying the variety of interactions with industry?', Research Policy 36(9), 1295-1313.

D'Este, P. \& Perkmann, M. (2011), 'Why do academics engage with industry? The entrepreneurial university and individual motivations', The Journal of Technology Transfer 36(3), 316-339.

DIUS (2008). Innovation Nation. HM Stationary Office, London.

Dutrenit, G. \& Arza, V. (2010), 'Channels and benefits of interactions between public research organisations and industry: comparing four Latin American countries', Science and Public Policy 37 (7), 541-553.

Fabrizio, K. R. \& Di Minin, A. (2008), 'Commercializing the laboratory: Faculty patenting and the open science environment', Research Policy 37(5), 914-931.

Gourieroux, C.; Monfort, A. \& Trognon, A. (1984), 'Pseudo maximum likelihood methods: applications to Poisson models', Econometrica 52(3), 701-720.

Grimpe, C. and Fier, H. (2010). 'Informal university technology transfer: a comparison between the United States and Germany’ The Journal of Technology Transfer 35(6): 1-14.

Gulbrandsen, M. \& Smeby, J. C. (2005), 'Industry Funding and University Professors' Research Performance', Research Policy 34(6), 932-950.

Hottenrott, H. \& Thorwarth, S. (2011), 'Industry funding of university research and scientific productivity', Kyklos 64(4), 534-555.

Imbens, G. (2000), 'The role of the propensity score in estimating dose-response functions', Biometrika 87(3), 706-710.

Jensen, R., Thursby, J. and Thursby, M. (2010). 'University-Industry Spillovers, Government Funding, and Industrial Consulting’, NBER Working Papers n. 15732.

Krimsky, K. (2003). Science in the private interest: has the lure of profits corrupted the virtue of biomedical research? Rowman \& Littlefield, Lanham.

Landry, R., Saihi, M., Amara, N. and Ouimet, M. (2010). 'Evidence On How Academics Manage Their Portfolio Of Knowledge Transfer Activities’ Research Policy 39 (10): 1387-1403.

Larsen, M. T. (2011), The implications of academic enterprise for public science: An overview of the empirical evidence, Research Policy, 40(1): 6-19.

Lechner, M. (2001). "Identification and estimation of causal effects of multiple treatments under the conditional independence assumption", Econometric evaluation of labour market policies, Physica-Springer, 2001, pp. 43-58.

Lechner, M. (2002). 'Some practical issues in the evaluation of heterogeneous labour market programmes by matching methods' Journal of the Royal Statistical Society: Series A (Statistics in Society) 165 (1): 59-82.

Link, A. N. and Scott, J. T. "U.S. science parks: the diffusion of an innovation and its effects on the academic missions of universities," International Journal of Industrial Organization (21:9), 2003, pp. 1323-1356.

Link, A. N., Siegel, D.S. \& Bozeman, B. (2007), 'An empirical analysis of the propensity of academics to engage in informal university technology transfer', Industrial and Corporate Change 16 (4): 641-655.

Manjarrés-Henriquez, L.; Gutiérrez-Gracia, A.; Carrión-Garcia, A. \& Vega-Jurado, J. (2009), 'The Effects of University--Industry Relationships and Academic Research On Scientific Performance: Synergy or Substitution?', Research in Higher Education 50(8), 795-811. 
Mansfield, E. (1995). 'Academic research underlying industrial innovations: sources, characteristics, and financing, The Review of Economics and Statistics 77 (1) (1995), pp. 55-65.

Mitchell, J.E. \& Rebne, D.S. (1995), 'The nonlinear effects of teaching and consulting on academic research productivity’, Socio-Economic Planning Sciences 29, 47-57.

Moffitt, R. (2008), 'Estimating marginal treatment effects in heterogeneous populations', Annales d'Economie et de Statistique 91-92, 239-261.

Mowery, D. C.; Sampat, B. N. \& Ziedonis, A. A. (2002), 'Learning to Patent: Institutional Experience, Learning, and the Characteristics of U.S. University Patents After the Bayh-Dole Act, 1981-1992', Management Science 48(1), 73-89.

OECD (2003), Turning science into business, patenting and licensing at public research organisations. OECD: Paris.

Perkmann, M. \& Walsh, K. (2008), 'Engaging the scholar: Three types of academic consulting and their impact on universities and industry', Research Policy 37(10), 1884-1891.

Rebne, D. (1989). 'Faculty consulting and scientific knowledge - a traditional universityindustry linkage’ Education Administration Quarterly 25 (4): 338-357.

Rosenbaum, P. and Rubin, D. (1983). 'The central role of the propensity score in observational studies for causal effects’ Biometrika 70 (1): 41-55.

Rosenberg, N. and Nelson, R.R. (1994), 'American universities and technical advance in industry', Research Policy 23, 323-348.

Schartinger, D., Rammer, C., Fischer, M. M., Fröhlich, J. (2002). Knowledge interactions between universities and industry in Austria: Sectoral patterns and determinants, Research Policy 31(3): 303-328.

Stephan, P., Gurmu, S., Sumell, A. and Black, G. (2007), Who’s patenting in the University? Evidence from the Survey of Doctorate Recipients, Economics of Innovation and New Technology, 16(2), 71-99

Terza, J. (1998), 'Estimating count data models with endogenous switching: Sample selection and endogenous treatment effects', Journal of Econometrics 84(1), 129-154.

Thursby, J., Jensen, R. and Thursby, M. (2001). Objectives, characteristics and outcomes of university licensing: a survey of major U.S. universities, Journal of Technology Transfer 26(1-2): 59-72.

Thursby, M.; Thursby, J. \& Gupta-Mukherjee, S. (2007), 'Are there real effects of licensing on academic research? A life cycle view', Journal of Economic Behavior and Organization 63(4), 577$-598$.

Toole, A. A. \& Czarnitzki, D. (2010), 'Commercializing Science: Is There a University "Brain Drain" from Academic Entrepreneurship?', Management Science 56(9), 1599-1614.

Van-Looy, B.; Callaert, J. \& Debackere, K. (2006), 'Publication and Patent Behavior of Academic Researchers: Conflicting, Reinforcing or Merely Co-existing?', Research Policy 35(4), 596-608.

Veugelers, R. and Cassiman, B. (2005) "R\&D cooperation between firms and universities. Some empirical evidence from Belgian manufacturing," International Journal of Industrial Organization (23:5-6), 355-379.

Xie, Yu, Jennie E. Brand, and Ben Jann. (2012) "Estimating heterogeneous treatment effects with observational data." Sociological Methodology 42(1), 314-347. 
Table 1. Proportion of active researchers who engage in consulting and R\&D contracts over the period 1999-2004, by university (\%):

\begin{tabular}{lccc}
\hline & Consulting & R\&D Contracts & N. obs. \\
\hline UA & 43 & 29 & 349 \\
UJI & 44 & 33 & 189 \\
UMH & 51 & 16 & 249 \\
UPV & 68 & 27 & 881 \\
UV & 36 & 41 & 1010 \\
Total & 49 & 32 & 2678 \\
\hline
\end{tabular}

Table 2. Proportion of active researchers who engage in consulting and R\&D contracts over the period 1999-2004, by field of science (\%):

\begin{tabular}{lccc}
\hline \multicolumn{1}{c}{ Scientific Field } & Consulting & R\&D Contracts & N. obs. \\
\hline Natural \& Exact Sc. & 42.6 & 32.0 & 1040 \\
Engineering & 72.2 & 32.7 & 593 \\
Medical Sc & 41.3 & 30.6 & 196 \\
Social Sc. \& Humanities & 42.5 & 32.4 & 817 \\
Total & 49.1 & 32.9 & $2646^{*}$ \\
\hline
\end{tabular}

* There are 32 missing values regarding scientific field. 
Table 3: Description of the variables used in the regressions

\begin{tabular}{|c|c|}
\hline Variable & Description and scale \\
\hline NumberPub & $\begin{array}{l}\text { Scientific Production. } N^{\circ} \text { of articles published by each researcher in journals ISI 2003-2004 } \\
\text { period }\end{array}$ \\
\hline DAcademicConsulting & $\begin{array}{l}\text { Dummy variable equal to } 1 \text { if the academic scientist } i \text { engaged in academic consulting in the } \\
1999-2002 \text { period }\end{array}$ \\
\hline VConsulting & $\begin{array}{l}\text { Ordered variable taking on three different values according to the amount of monetary } \\
\text { income that scientist } i \text { got from consulting activity in period 1999-2002. It takes the following } \\
\text { values: } 0 \text { (scientist did not carry out any consulting activity), 1(the amount of monetary } \\
\text { income from consulting contracts is lower than the median value) and } 2 \text { (the amount of } \\
\text { monetary income from consulting contracts is higher than the median value) }\end{array}$ \\
\hline ResearchAbility & Number of “sexenios”relative to the number of years in academy. \\
\hline Focus & $\begin{array}{l}\text { Average number of research contracts over the total number of research projects (i.e. research } \\
\text { contracts plus competitive research projects) obtained in the period 1999-2002. }\end{array}$ \\
\hline QualityDpt & $\begin{array}{l}\text { Average number of citations per publication at the department level, normalized for } \\
\text { differences among fields (see Waltman et al., 2011) }\end{array}$ \\
\hline ContractRD & $\begin{array}{l}\text { Average number of research contracts funded by private companies or public administrations } \\
\text { in the } 1999-2002 \text { period }\end{array}$ \\
\hline CompetitiveRD & $\begin{array}{l}\text { Average number of research projects funded by local. national or European public bodies in } \\
\text { the } 1999-2002 \text { period }\end{array}$ \\
\hline Experience & $\begin{array}{l}\text { Number of "quinquenios" obtained by the professor during their life work: } 1 \text { "quinquenio" is } \\
\text { equal to } 5 \text { years of work experience }\end{array}$ \\
\hline DAcademicPosition & $\begin{array}{l}\text { Dummy Variable of 1-3. Academic position of the scientist : 1.Other; 2. Lecturer and } 3 . \\
\text { Professor }\end{array}$ \\
\hline DScientificField & $\begin{array}{l}\text { Dummy Variable of 1-4. Researcher's scientific field to which the researcher belongs: } 1 . \\
\text { Natural and exact sciences; } 2 \text {. Engineering; 3. Medical Science and } 4 \text {. Social Science and } \\
\text { humanities }\end{array}$ \\
\hline Duniversity & $\begin{array}{l}\text { Dummy variable of } 1-5 \text {. University to which the researcher belongs: } 1 . \mathrm{UA} ; 2 . \mathrm{UJI} \text {; 3.UMH; } \\
\text { 4.UPV; } 5 . \mathrm{UV}\end{array}$ \\
\hline
\end{tabular}


Table 4. Descriptive statistics and Spearman's correlation coefficients $(n=2402)$

\begin{tabular}{|c|c|c|c|c|c|c|c|c|c|c|c|c|c|c|c|c|c|c|c|c|c|}
\hline & & iviean & S. D. & IVIIn & ivax & (1) & (ट) & (3) & (4) & (5) & (b) & (1) & (ठ) & (马) & (10) & (11) & (12) & (13) & (14) & (15) & (10) \\
\hline (1) & NumberPub & 6.03 & 11.80 & 0 & 99 & 1 & & & & & & & & & & & & & & & \\
\hline (2) & DAcademicConsulting & 0.36 & 0.48 & 0 & 1 & -0.03 & 1 & & & & & & & & & & & & & & \\
\hline (3) & MediumVConsulting & 0.14 & 0.35 & 0 & 1 & 0.03 & 0.65 & 1 & & & & & & & & & & & & & \\
\hline (4) & HighVConsulting & 0.14 & 0.35 & 0 & 1 & -0.05 & 0.64 & -0.17 & 1 & & & & & & & & & & & & \\
\hline (5) & QualityDpt & 0.58 & 0.61 & 0 & 9.4 & -0.01 & 0.03 & 0.02 & 0.02 & 1 & & & & & & & & & & & \\
\hline (6) & ResearchAbility & 0.51 & 0.39 & 0 & 1 & 0.33 & -0.15 & 0.02 & -0.12 & 0.02 & 1 & & & & & & & & & & \\
\hline (7) & Focus & 0.17 & 0.32 & 0 & 1 & -0.04 & 0.11 & 0.06 & 0.13 & -0.01 & -0.04 & 1 & & & & & & & & & \\
\hline (8) & CompetitiveRD & 0.30 & 0.49 & 0 & 12.5 & 0.24 & 0.03 & 0.03 & 0.03 & 0.04 & 0.32 & -0.01 & 1 & & & & & & & & \\
\hline (9) & ContractRD & 0.15 & 0.55 & 0 & 17.5 & 0.04 & 0.16 & 0.09 & 0.20 & 0.01 & 0.08 & 0.46 & 0.54 & 1 & & & & & & & \\
\hline (10) & Experience & 3.27 & 1.77 & 0 & 8 & 0.04 & 0.06 & 0.00 & 0.12 & 0.08 & 0.21 & 0.09 & 0.21 & 0.11 & 1 & & & & & & \\
\hline (11) & Others & 0.20 & 0.40 & 0 & 1 & -0.14 & 0.05 & 0.01 & -0.02 & 0.00 & -0.44 & -0.06 & -0.24 & -0.09 & -0.46 & 1 & & & & & \\
\hline (12) & Lecturer & 0.53 & 0.50 & 0 & 1 & -0.08 & -0.14 & -0.04 & -0.11 & -0.01 & 0.13 & 0.01 & -0.05 & -0.04 & -0.11 & -0.52 & 1 & & & & \\
\hline (13) & Professor & 0.27 & 0.45 & 0 & 1 & 0.21 & 0.11 & 0.04 & 0.14 & 0.01 & 0.25 & 0.04 & 0.26 & 0.13 & 0.53 & -0.30 & -0.65 & 1 & & & \\
\hline (14) & Natural \& Exact Sciences & 0.40 & 0.49 & 0 & 1 & 0.23 & -0.06 & 0.03 & -0.08 & 0.15 & 0.17 & -0.05 & 0.09 & -0.02 & 0.05 & -0.05 & 0.06 & -0.02 & 1 & & \\
\hline (15) & Medical Sciences & 0.08 & 0.27 & 0 & 1 & 0.03 & -0.05 & -0.01 & -0.03 & 0.00 & 0.07 & -0.01 & 0.03 & 0.00 & 0.07 & -0.06 & 0.04 & 0.00 & -0.23 & 1 & \\
\hline (16) & Social Sc. \& Humanities & 0.32 & 0.47 & 0 & 1 & -0.30 & -0.10 & -0.06 & -0.03 & -0.13 & -0.03 & 0.01 & -0.06 & -0.02 & 0.03 & -0.07 & 0.06 & -0.01 & -0.55 & -0.20 & 1 \\
\hline$(17)$ & Engineering & 0.21 & 0.41 & 0 & 1 & 0.04 & 0.23 & 0.04 & 0.17 & -0.02 & -0.21 & 0.06 & -0.06 & 0.05 & -0.15 & 0.18 & -0.17 & 0.03 & -0.42 & -0.15 & -0.35 \\
\hline
\end{tabular}

Beyond 0.04 the correlation coefficients are significant at standard levels (5\%).

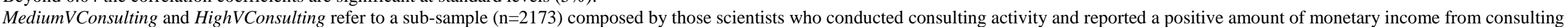
contracts in the 1999-2002 period. The sample contains 229 scientists who, despite engaging in consulting activity, did not report any income from consulting contracts. 
Table 5. Comparison of means of scientific productivity in the different group of academic scientists

\begin{tabular}{|l|c|c|c|}
\hline \multirow{2}{*}{ Group } & \multicolumn{3}{|c|}{$\begin{array}{c}\text { Scientific productivity } \\
\text { T- test }\end{array}$} \\
\cline { 2 - 3 } & $\mathbf{N}^{\mathbf{0}}$ Obs & Mean & T \\
\hline 1. Scientist not engaged in consulting & 1702 & 6.4 & $2.898^{* *}$ \\
\hline 2. Scientist engaged in consulting & 976 & 5.0 & \\
\hline
\end{tabular}

Note: ** $\mathrm{p}<0.05$ 
Table 6: Regression results on the effect of engaging in academic consulting (1a-1c) and the amount of academic consulting (2a-2c) on scientific productivity

\begin{tabular}{|c|c|c|c|c|c|c|}
\hline & (1a) & (1b) & (1c) & (2a) & (2b) & $(2 c)$ \\
\hline & OLS & $\begin{array}{c}\text { QML } \\
\text { Poisson }\end{array}$ & $\begin{array}{c}\text { Zero- } \\
\text { inflated } \\
\text { Poisson }\end{array}$ & OLS & $\begin{array}{c}\text { QML } \\
\text { Poisson }\end{array}$ & $\begin{array}{c}\text { Zero- } \\
\text { inflated } \\
\text { Poisson }\end{array}$ \\
\hline DAcademicConsulting & $\begin{array}{c}-1.54 * * * \\
(0.43)\end{array}$ & $\begin{array}{c}-0.22 * * * \\
(0.06)\end{array}$ & $\begin{array}{c}-0.18^{* * *} \\
(0.06)\end{array}$ & --- & --- & --- \\
\hline \multicolumn{7}{|l|}{ VConsutling (ref.cat.: Zero) } \\
\hline Medium & --- & --- & --- & $\begin{array}{l}-0.63 \\
(0.52)\end{array}$ & $\begin{array}{l}-0.11 \\
(0.07)\end{array}$ & $\begin{array}{l}-0.11 \\
(0.07)\end{array}$ \\
\hline High & --- & --- & --- & $\begin{array}{c}-3.04^{* * *} \\
(0.64)\end{array}$ & $\begin{array}{c}-0.44 * * * \\
(0.10)\end{array}$ & $\begin{array}{c}-0.36^{* * *} \\
(0.10)\end{array}$ \\
\hline ResearchAbility & $\begin{array}{c}8.91 * * * \\
(0.65)\end{array}$ & $\begin{array}{c}1.81 * * * \\
(0.11)\end{array}$ & $\begin{array}{c}1.27 * * * \\
(0.11)\end{array}$ & $\begin{array}{c}8.28 * * * \\
(0.67)\end{array}$ & $\begin{array}{c}1.65 * * * \\
(0.12)\end{array}$ & $\begin{array}{c}1.19 * * * \\
(0.12)\end{array}$ \\
\hline QualityDpt & $\begin{array}{c}-0.58 * * \\
(0.24)\end{array}$ & $\begin{array}{l}-0.05 \\
(0.05)\end{array}$ & $\begin{array}{l}-0.07 \\
(0.05)\end{array}$ & $\begin{array}{c}-0.52 * * \\
(0.25)\end{array}$ & $\begin{array}{l}-0.04 \\
(0.05)\end{array}$ & $\begin{array}{l}-0.04 \\
(0.05)\end{array}$ \\
\hline Focus & $\begin{array}{c}0.16 \\
(0.67)\end{array}$ & $\begin{array}{c}0.02 \\
(0.14)\end{array}$ & $\begin{array}{l}-0.14 \\
(0.14)\end{array}$ & $\begin{array}{l}-0.36 \\
(0.70)\end{array}$ & $\begin{array}{l}-0.26 \\
(0.16)\end{array}$ & $\begin{array}{c}-0.33^{* *} \\
(0.15)\end{array}$ \\
\hline CompetitiveRD & $\begin{array}{c}5.52 * * * \\
(1.08)\end{array}$ & $\begin{array}{c}0.80 * * * \\
(0.14)\end{array}$ & $\begin{array}{c}0.63 * * * \\
(0.13)\end{array}$ & $\begin{array}{c}5.10 * * * \\
(1.15)\end{array}$ & $\begin{array}{c}0.76 * * * \\
(0.15)\end{array}$ & $\begin{array}{c}0.58 * * * \\
(0.15)\end{array}$ \\
\hline CompetitiveRD $D^{2}$ & $\begin{array}{l}-0.17 \\
(0.48)\end{array}$ & $\begin{array}{c}-0.13^{* *} \\
(0.06)\end{array}$ & $\begin{array}{l}-0.09 * \\
(0.05)\end{array}$ & $\begin{array}{c}-0.29 \\
(0.56)\end{array}$ & $\begin{array}{c}-0.15^{* *} \\
(0.07)\end{array}$ & $\begin{array}{l}-0.09 \\
(0.06)\end{array}$ \\
\hline ContractRD & $\begin{array}{c}0.33 \\
(1.20)\end{array}$ & $\begin{array}{l}-0.11 \\
(0.14)\end{array}$ & $\begin{array}{l}-0.01 \\
(0.13)\end{array}$ & $\begin{array}{c}1.13 \\
(1.34)\end{array}$ & $\begin{array}{c}0.25 \\
(0.18)\end{array}$ & $\begin{array}{c}0.20 \\
(0.18)\end{array}$ \\
\hline ContractRD $D^{2}$ & $\begin{array}{l}-0.17 \\
(0.27)\end{array}$ & $\begin{array}{c}0.04 \\
(0.03)\end{array}$ & $\begin{array}{c}0.02 \\
(0.03)\end{array}$ & $\begin{array}{l}-0.35 \\
(0.30)\end{array}$ & $\begin{array}{l}-0.05 \\
(0.04)\end{array}$ & $\begin{array}{l}-0.04 \\
(0.04)\end{array}$ \\
\hline Experience & $\begin{array}{c}0.68 \\
(0.54)\end{array}$ & $\begin{array}{c}0.23^{* *} \\
(0.10)\end{array}$ & $\begin{array}{l}0.19 * \\
(0.10)\end{array}$ & $\begin{array}{c}0.85 \\
(0.58)\end{array}$ & $\begin{array}{c}0.27 * * \\
(0.11)\end{array}$ & $\begin{array}{c}0.24 * * \\
(0.11)\end{array}$ \\
\hline Experience $^{2}$ & $\begin{array}{l}-0.07 \\
(0.09)\end{array}$ & $\begin{array}{c}-0.03^{* *} \\
(0.01)\end{array}$ & $\begin{array}{c}-0.02 * \\
(0.01)\end{array}$ & $\begin{array}{l}-0.08 \\
(0.09)\end{array}$ & $\begin{array}{c}-0.03^{* *} \\
(0.01)\end{array}$ & $\begin{array}{c}-0.03^{* *} \\
(0.01)\end{array}$ \\
\hline Academic position dummies & Inc. & Inc. & Inc. & Inc. & Inc. & Inc. \\
\hline Scientific disciplines dummies & Inc. & Inc. & Inc. & Inc. & Inc. & Inc. \\
\hline Universit dummies & Inc. & Inc. & Inc. & Inc. & Inc. & Inc. \\
\hline $\begin{array}{l}\text { Experience } * \text { ScientificField } \\
\text { dummies }\end{array}$ & Inc. & Inc. & Inc. & Inc. & Inc. & Inc. \\
\hline Experience $*$ Position dummies & Inc. & Inc. & Inc. & Inc. & Inc. & Inc. \\
\hline $\begin{array}{l}\text { University*Position*ScientificField } \\
\text { dummies }\end{array}$ & Inc. & Inc. & Inc. & Inc. & Inc. & Inc. \\
\hline Constant & $\begin{array}{c}-3.52 * * \\
(1.40)\end{array}$ & $\begin{array}{c}-2.45^{* * *} \\
(0.74)\end{array}$ & $\begin{array}{c}-1.70 * * \\
(0.82)\end{array}$ & $\begin{array}{c}-41.38 * * * \\
(10.42)\end{array}$ & $\begin{array}{c}1.17 \\
(0.77)\end{array}$ & $\begin{array}{l}1.86 * * \\
(0.76)\end{array}$ \\
\hline Log-likelihood & -8586.24 & -8288.94 & -7214.29 & -7754.21 & -7489.60 & -6744.76 \\
\hline \# of observations & 2402 & 2402 & 2402 & 2173 & 2173 & 2173 \\
\hline
\end{tabular}

$* \mathrm{p}<0.10 . .{ }^{* *} \mathrm{p}<0.05 . .{ }^{* * *} \mathrm{p}<0.01$.

Robust standard errors and degrees of freedom are in parentheses.

Results for the inflation model of the Zero-inflated Poisson are omitted for space reasons and available from the authors upon request.

In columns $2 \mathrm{a}, 2 \mathrm{~b}$ and $2 \mathrm{c}$ three different intensities of consulting activity are taken into consideration and refer to the amount of monetary income from consulting contracts: (i) "high" (total amount of monetary income from consulting higher than the median value); (ii) "medium” (total amount of monetary income from consulting lower than the median value) and (iii) "zero" (those reporting no consulting contracts). 
QualityDpt

DAcademicConsulting

ResearchAbility

0.05

$-0.78 * * *$

$(0.16)$

Focus

$-0.96 * * *$

CompetitiveRD

CompetitiveRD ${ }^{2}$

ContractRD

ContractRD $D^{2}$

$-0.42 * * *$

Experience

$0.49 * * *$

Experience $^{2}$

$-0.04^{*}$

(0.02)

Academic position dummies

Inc.

Scientific disciplines dummies

Inc.

Universit dummies

Inc.

Experience*ScientificField dummies

Inc.

Experience*Position dummies

Inc.

University*Position*ScientificField dummies

Inc.

Constant

Log-likelihood

\# of observations

Robust standard errors and degrees of freedom are in parentheses. 
Table 8: Estimation of the average effect of consulting on the scientific productivity of academic scientists engaging in consulting activity

\begin{tabular}{lccc}
\hline & \multicolumn{2}{c}{ Outcome variable: NumberPub } \\
\hline Matching Algorithm & $\begin{array}{c}\text { Nearest } \\
\text { Neighbour }^{ \pm}\end{array}$ & Radius & Kernel $^{+}$ \\
\hline ATT: DAcademicConsulting & $-1.46^{* *}$ & $-1.7^{* * *}$ & $-1.81^{* * *}$ \\
\# of treated obs & 829 & 829 & 829 \\
\# of untreated obs & 1535 & 1535 & 1535 \\
Quality of matching & & 0.12 & 0.12 \\
\hline Pseudo $R^{2}$ before & 0.12 & 0 \\
Pseudo $R^{2}$ after & 19.65 & 19.65 & 19.65 \\
Mean absolute standardised bias before matching & 1.83 & 2.12 & 1.59 \\
Mean absolute standardised bias after matching & Yes & Yes & Yes \\
T-tests for equality of means in the treated and non-treated groups & & 0 \\
\hline
\end{tabular}

** $\mathrm{p}<0.05 . . * * * \mathrm{p}<0.01$.

${ }^{ \pm}$The matching has been carried out using 5 neighbours for each treated observation

${ }^{+}$The calculation of the standard errors is done using bootstrap with 500 replications (see Lechner.. 2002) 
Table 9: Treatment effects estimations for different scientific fields

\begin{tabular}{|c|c|c|c|c|c|c|c|c|c|c|c|c|}
\hline \multirow[b]{2}{*}{ Matching Algorithm } & \multicolumn{3}{|c|}{ Natural and Exact Sciences } & \multicolumn{2}{|c|}{ Medical Sciences } & \multirow[b]{2}{*}{ Kernel $^{+}$} & \multicolumn{3}{|c|}{ Social Sciences and Humanities } & \multicolumn{3}{|c|}{ Engineering and Technology } \\
\hline & $\begin{array}{c}\text { Nearest } \\
\text { Neighbor }^{ \pm}\end{array}$ & Radius & Kernel $^{+}$ & $\begin{array}{c}\text { Nearest } \\
\text { Neighbor }^{ \pm}\end{array}$ & Radius & & $\begin{array}{c}\text { Nearest } \\
\text { Neighbor }^{ \pm}\end{array}$ & Radius & Kernel $^{+}$ & $\begin{array}{c}\text { Nearest } \\
\text { Neighbor }^{ \pm}\end{array}$ & Radius & Kernel $^{+}$ \\
\hline ATT: DAcademicConsulting & $-1.49 *$ & $-2.15^{* *}$ & $-2.29 * *$ & 1.93 & 1.73 & 2.35 & -0.35 & -0.33 & -0.38 & $-3.54 * *$ & $-3.02 * *$ & $-2.9 * *$ \\
\hline \# of treated obs & 292 & 292 & 292 & 48 & 48 & 48 & 209 & 209 & 209 & 275 & 275 & 275 \\
\hline \# of untreated obs & 642 & 642 & 642 & 134 & 134 & 134 & 544 & 544 & 544 & 215 & 215 & 215 \\
\hline \multicolumn{13}{|l|}{ Quality of matching } \\
\hline Pseudo R2 before & 0.11 & 0.11 & 0.11 & 0.12 & 0.12 & 0.12 & 0.11 & 0.11 & 0.11 & 0.08 & 0.08 & 0.08 \\
\hline Pseudo R2 after & 0 & 0 & 0 & 0.02 & 0.02 & 0.02 & 0.02 & 0.02 & 0.02 & 0.01 & 0.01 & 0.01 \\
\hline $\begin{array}{l}\text { Mean absolute standardised bias before } \\
\text { matching }\end{array}$ & 20.5 & 20.5 & 20.5 & 28.6 & 28.6 & 28.6 & 15.9 & 15.9 & 15.9 & 18.5 & 18.5 & 18.5 \\
\hline $\begin{array}{l}\text { Mean absolute standardised bias after } \\
\text { matching }\end{array}$ & 3.8 & 3.3 & 3.9 & 8.5 & 5.4 & 6.4 & 6.4 & 6.3 & 6 & 3.6 & 3 & 3.4 \\
\hline $\begin{array}{l}\text { T-tests for equality of means in the treated } \\
\text { and non-treated groups }\end{array}$ & yes & yes & yes & yes & yes & yes & yes & yes & yes & yes & yes & yes \\
\hline
\end{tabular}

and non-treated groups

${ }^{ \pm}$The matching has been carried out using 5 neighbours for each treated observation

${ }^{+}$The calculation of the standard errors is done using bootstrap with 500 replications (see Lechner.. 2002) 
Table 10: Estimation of multiple treatment effects for overall consulting and different scientific fields

\begin{tabular}{|c|c|c|c|c|c|c|c|c|c|c|c|c|}
\hline & \multicolumn{3}{|c|}{ Overall } & \multicolumn{3}{|c|}{ Natural and Exact Sciences } & \multicolumn{3}{|c|}{ Social Sciences and Humanities } & \multicolumn{3}{|c|}{ Engineering and Technology } \\
\hline & $\begin{array}{c}\text { High vs } \\
\text { Zero }\end{array}$ & $\begin{array}{l}\text { High vs } \\
\text { Medium }\end{array}$ & $\begin{array}{c}\text { Medium vs } \\
\text { Zero }\end{array}$ & $\begin{array}{l}\text { High vs } \\
\text { Zero }\end{array}$ & $\begin{array}{l}\text { High vs } \\
\text { Medium }\end{array}$ & $\begin{array}{c}\text { Medium vs } \\
\text { Zero }\end{array}$ & $\begin{array}{l}\text { High vs } \\
\text { Zero }\end{array}$ & $\begin{array}{l}\text { High vs } \\
\text { Medium }\end{array}$ & $\begin{array}{l}\text { Medium vs } \\
\text { Zero }\end{array}$ & $\begin{array}{c}\text { High vs } \\
\text { Zero }\end{array}$ & $\begin{array}{l}\text { High vs } \\
\text { Medium }\end{array}$ & $\begin{array}{c}\text { Medium vs } \\
\text { Zero } \\
\end{array}$ \\
\hline ATT: VConsulting & $-2.89 * * *$ & -1.3 & -0.64 & $-4.12 * *$ & -2.82 & -0.93 & $-0.45^{*}$ & -0.35 & -0.13 & $-4.03 * *$ & -1.55 & -2.03 \\
\hline \# of treated obs & 278 & 277 & 305 & 88 & 87 & 142 & 81 & 77 & 84 & 89 & 92 & 61 \\
\hline \# of untreated obs & 1454 & 299 & 1498 & 621 & 138 & 642 & 527 & 84 & 527 & 190 & 55 & 215 \\
\hline \multicolumn{13}{|l|}{ Quality of matching } \\
\hline Pseudo R2 before & 0.15 & 0.14 & 0.07 & 0.2 & 0.13 & 0.08 & 0.13 & 0.12 & 0.06 & 0.16 & 0.27 & 0.15 \\
\hline Pseudo R2 after & 0 & 0 & 0 & 0.03 & 0.02 & 0 & 0.03 & 0.05 & 0.02 & 0.03 & 0.1 & 0.01 \\
\hline $\begin{array}{l}\text { Mean absolute standardised bias } \\
\text { before matching }\end{array}$ & 24.8 & 19.7 & 13.3 & 30.2 & 23.5 & 19.4 & 19.2 & 16.3 & 14.5 & 20.6 & 29.5 & 21.1 \\
\hline $\begin{array}{l}\text { Mean absolute standardised bias } \\
\text { after matching }\end{array}$ & 2.7 & 4.3 & 1.5 & 9.8 & 6.7 & 5 & 8.4 & 11.5 & 10.5 & 8.9 & 15.2 & 3.8 \\
\hline $\begin{array}{l}\text { T-tests for equality of means in the } \\
\text { treated and non-treated groups }\end{array}$ & yes & yes & yes & yes & yes & yes & yes & yes & yes & yes & yes & yes \\
\hline
\end{tabular}
treated and non-treated groups

Results of kernel matching are reported. The calculation of the standard errors is done using bootstrap with 500 replications (see Lechner.. 2002).

Three different intensities of treatment are taken into consideration and refer to the amount of monetary income from consulting activity: (i) "high" (total amount of consulting higher than the median value);;(ii) “medium” (total amount of consulting lower than the median value) and (iii) "zero" (those reporting no consulting contracts).

Results for "Medical sciences" are not reported due to the low number of observations available. 
Figure 1: Heterogeneous treatment effects of consulting on scientific productivity: Overall sample (all sc.fields)

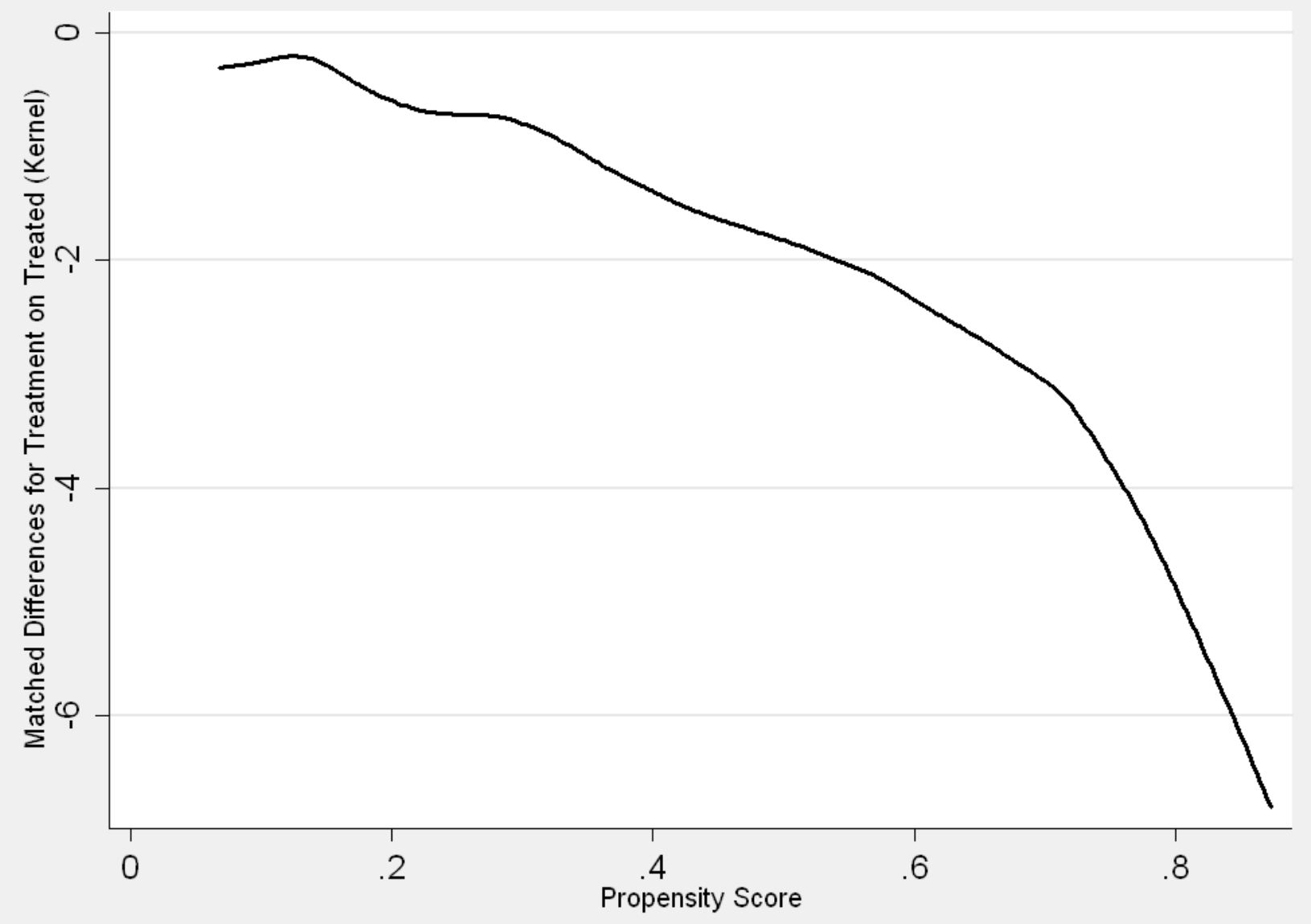


Figure 2: Heterogeneous treatment effects of consulting on scientific productivity by scientific field
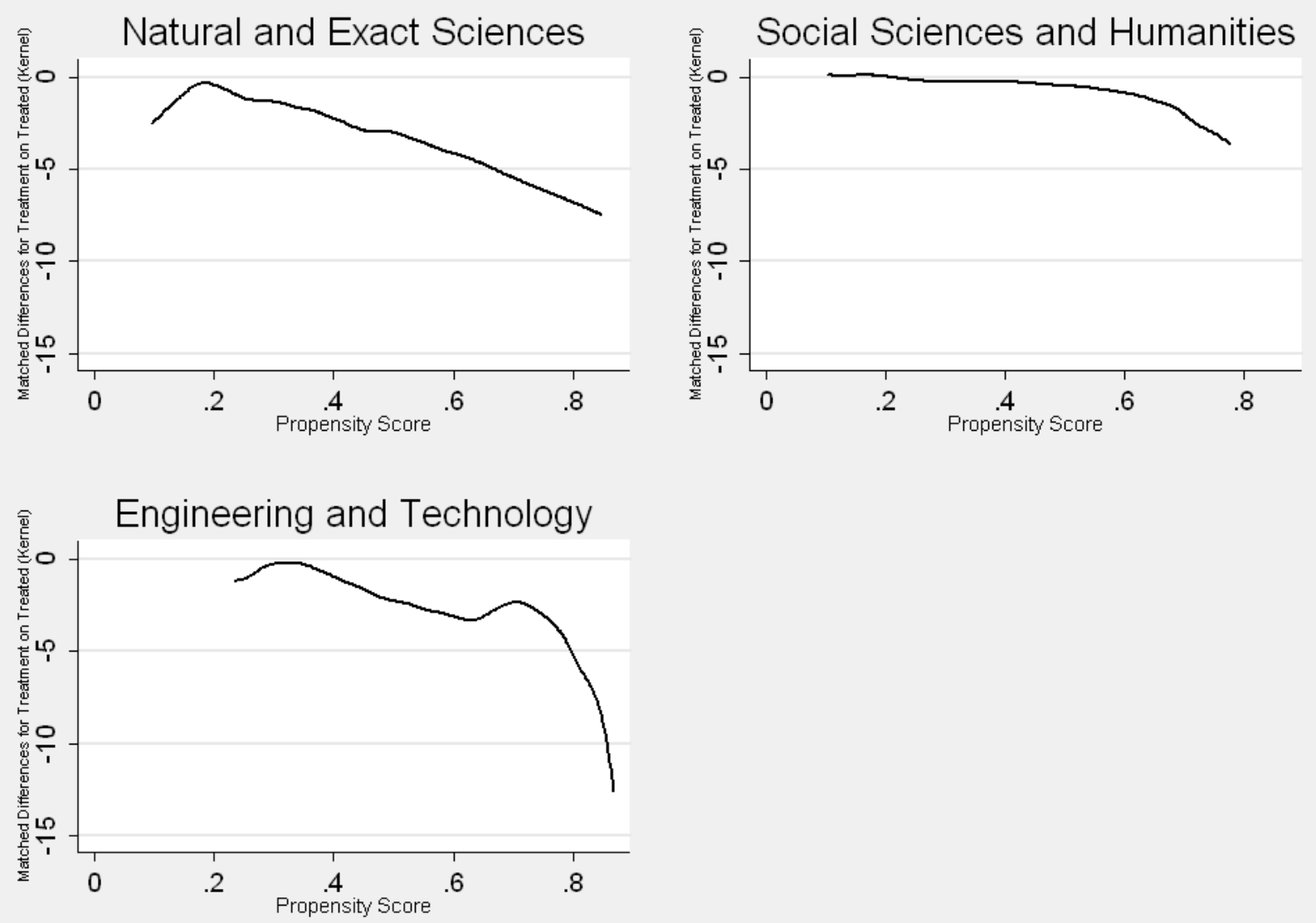